\title{
Absolute Isotopic Abundance Ratio and the Atomic Weight of Bromine
}

\author{
Edward J. Catanzaro, Thomas J. Murphy, Ernest L. Garner, and William R. Shields
}

(August 4, 1964)

\begin{abstract}
An absolute value is obtained for the isotopic abundance ratio of bromine using thermal emission mass spectrometers calibrated for bias by the use of samples of known isotopic composition prepared from nearly pure separated bromine isotopes. The resulting absolute $\mathrm{Br}^{79} \mathrm{Br}^{81}$ ratio is $1.02784 \pm 0.00190$ which yields an atomic weight $\left(\mathrm{C}^{12}=12\right)$ of 79.90363 \pm 0.00092 . The indicated uncertainties are overall limits of error based on 95 percent confidence limits for the mean and allowances for the effects of known sources of possible systematic error plus a component to cover possible natural variations in isotopic composition although no provable variations were noted among the $\mathrm{Br}^{79} / \mathrm{Br}^{81}$ ratios of 29 commercial and natural samples. Mass spectrometric determinations of the atomic weights of bromine and silver give a combining weight ratio of $\mathrm{AgBr} / \mathrm{Ag}=1.740752$.
\end{abstract}

\section{Introduction}

The atomic weights of silver, chlorine, and bromine form the classical basis for establishing atomic weights of many of the elements. Recent mass spectrometric determinations of the atomic weights of silver [1] ${ }^{1}$ and chlorine [2] have yielded values of $107.8682 \pm 0.0010^{2}$ and $35.45273+0.00092^{2}$ respectively. The present work extends the study to bromine.

A number of mass spectrometric determinations of bromine isotopic abundances have been reported in the literature. Blewett [3], Williams and Yuster [4], White and Cameron [5], and Cameron and Lippert [6] used electron bombardment ion sources and obtained values of $\mathrm{Br}^{79} \mathrm{Br}^{81}=1.026 \pm 0.026$, $1.021 \pm 0.004,1.0210 \pm 0.0020$, and $1.0217 \pm 0.0002$, respectively. However, none of these studies included a direct measurement of instrumental bias and, therefore, the resulting ratios were not absolute. White and Cameron [5] recognized that discrepancies between observers and instruments were probably due to mass discrimination occurring in the ion lenses of the sources, but were unable to measure or correct for this discrimination. Cameron and Lippert [6] took care to avoid fractionation during the chemical preparation of their samples, but only asserted that their method of measurement, sublimation of sodium bromide, was free of any instrumental discrimination. They did not attempt to verify this assertion in any manner.

In the present study, both mass spectrometers were calibrated for bias by the use of samples of 1 Figures in brackets indicate the literature references at the end of this paper.
2 Overall limit of error based on 95 percent confidence limits for the mean and allowances for effects of known sources of possible systematic error. known isotopic composition, prepared from nearly pure separated bromine isotopes. The measured biases were then used to obtain the absolute $\mathrm{Br}^{79}$ $\mathrm{Br}^{81}$ ratio of a reference sample of commercial sodium bromide. In addition, the $\mathrm{Br}^{79} / \mathrm{Br}^{81}$ ratios of a number of samples of commercial purified bromine and bromide from brines and minerals were also measured.

\section{Experimental Procedure}

\subsection{Mass Spectrometry}

All isotopic measurements were made using two nearly identical solid-souree single-focusing mass spectrometers equipped with 68-deg analyser tubes, $60-\mathrm{deg}$ magnet pole pieces and 12 -in. radii of curvature. Triple-filament rhenium ribbon $(1 \times 30$ mils $)$ sources were used and ion currents were measured by means of a vibrating reed electrometer with an expanded-scale recorder. Ratios were measured by varying the magnetic field at constant ion-accelerating voltage.

The bromide was deposited on the sample filaments in the form of ammoniacal solutions of silver bromide. Preliminary experiments showed that $\mathrm{Ag} \mathrm{Br}$ was far superior to $\mathrm{NaBr}$ with respect to signal stability during the mass spectrometric analyses. One drop of a $\mathrm{AgBr}$ solution containing $3 \mathrm{mg} \mathrm{Br} / \mathrm{ml}(\sim 0.06$ $\mathrm{mg} \mathrm{Br}$ ) was deposited on each filament and dried under a heat lamp. To minimize the variability of discrimination, all analyses were made in an identical manner. A strict pattern of filament heating was followed and a set of 10 measurements was made on a growing signal $\left(3-5 \times 10^{-13} \mathrm{~A}\right)$ between 38 and 52 min after the filaments were turned on. Analyses which did not follow the normal signal-growth pattern were discarded. 


\subsection{Puritication of the Separated Isotopes}

Electromagnetically separated isotopes in the form of sodium bromide were obtained from the Isotopes Division, Oak Ridge National Laboratory of the Union Carbide Nuclear Company. The $\mathrm{NaBr}^{79}$ and the $\mathrm{NaBr}^{81}$ were designated Series LM, Lot Number 1391(a) and Series LM, Lot Number 1392(a), respectively. The certificate of analysis accompanying each sample indicated a high degree of cationic purity but did not exclude the possible presence of other halides or pseudohalides. Since the bromide ion concentration of solutions was to be determined by silver coulometry and since the halides iodide and chloride, and pseudo-halides, cyanide and thiocyanate, would react with silver to form insoluble compounds [7], the iostopic samples were further purified to insure the removal of these impurities.

Each separated isotope sample (about $5 \mathrm{~g}$ ) was divided in half and treated as follows: The sodium bromide (about $2.5 \mathrm{~g}$ ) was dissolved in a small amount of water and transferred to a $300 \mathrm{ml}$ three-neck distilling apparatus like that described by Murphy, Clabaugh, and Gilchrist [8]. The solution volume was increased to $100 \mathrm{ml}$ and $0.2 \mathrm{ml}$ of redistilled nitric acid was added. Twenty milliliters of dilute ammonium hydroxide $(1: 9)$ was added to the receiver flask. The solution was then heated to boiling, and refluxed for $2 \mathrm{hr}$ while a stream of halidefree air was drawn through the system. The heat was then increased and about $10 \mathrm{ml}$ of the solution was distilled into the dilute $\mathrm{NH}_{4} \mathrm{OH}$ solution.

This procedure will oxidize iodide to iodine [9] and remove it from solution while only a small amount of bromide is lost. Tests based on the insolubility of silver iodide in ammoniacal solution have shown that when $0.025 \mathrm{mg}$ of iodide ion was added to a solution containing $2.5 \mathrm{~g}$ of $\mathrm{NaBr}$ and treated as above, the recovery of iodine was complete, so that in terms of the $\mathrm{NaBr}$ the iodine concentration in the solution would be less than 0.001 percent. Tests based on the insolubility of silver cyanide have also shown that if cyanide were present, almost all of it would be removed by the above procedure either as hydrogen cyanide or as cyanogen.

Ten milliliters of water and $20 \mathrm{ml}$ of redistilled nitric acid were added to the sodium bromide solution and the solution was refluxed while a stream of halide free air was drawn through the solution. The bromine liberated was slowly distilled into a solution containing a 20 percent excess of the stoichiometric quantity of sodium carbonate and $5 \mathrm{ml}$ of 30 percent hydrogen peroxide. The distillation was continued until only a slight color of bromine remained in the distilland.

Dilute nitric acid $(1: 5)$ has been shown to oxidize bromide to bromine quantitatively [8] without oxidizing chloride to chlorine. Chloride analyses [8] of the distillands after removal of the bromine showed that the chloride concentration was less than 0.001 percent in terms of the $\mathrm{NaBr}$ present.

After the distillation of bromine was completed, the distillate was heated on a steam bath until the hydrogen peroxide was decomposed. This oxidation by hydrogen peroxide removed any cyanide [10] or thiocyanate [11] that might have distilled with the bromine. Tests, based on the insolubility of silver cyanide and silver thiocyanate, showed that solutions prepared in this manner contained less than 0.001 percent $(\mathrm{CN})^{-}$or 0.001 percent $(\mathrm{SCN})^{-}$in terms of the $\mathrm{NaBr}$ present.

The solution was then transferred to a platinum dish and evaporated to dryness. The dish and contents were covered and heated to $550{ }^{\circ} \mathrm{C}$ for $1 / 2 \mathrm{hr}$ in an electric furnace to convert any bromate present to bromide. Any nitrate present would be converted to nitrite and cause difficulty in the bromine titration. Therefore, the salt mixture, which contained sodium bromide, sodium nitrite, and the excess sodium carbonate, was dissolved in $50 \mathrm{ml}$ of $\mathrm{H}_{2} \mathrm{O}$ and 1 drop of phenolphthalein indicator solution was added. The solution was neutralized to the phenolphthalein end point with (1:9) acetic acid. An equivalent amount of the dilute acetic acid plus a $1-\mathrm{ml}$ excess was then added to neutralize the bicarbonate produced and make the solution slightly acid. Two milliliters of 30 percent hydrogen peroxide was then added and the solution was heated overnight on a steam bath. Under these conditions nitrite is oxidized to nitrate [12] and the prolonged heating destroys the excess peroxide.

Analyses of sodium bromide solutions prepared in the above manner have shown that the solutions contained less than 0.0005 percent bromate ion, less than 0.0005 percent nitrite ion, and less than 0.0005 percent hydrogen peroxide in terms of the sodium bromide present. The bromate test was based on the reaction of bromate with bromide in acid solution to produce bromine which was detected with o-tolidine. Nitrite was determined with phenylenediamine [13]. The test for hydrogen peroxide was based on its reaction with titanium to form a colored complex [14].

This purification procedure was repeated on the remaining portions of the separated isotope samples for groups II.

Iodide was not detected in either of the starting isotopic samples. Chloride was found in both the $\mathrm{NaBr}^{70}$ and the $\mathrm{NaBr}^{81}$ to the extent of 0.13 percent and 0.11 percent, respectively. As stated previously, tests have shown that the purification procedure reduced the chloride content of the sodium bromide to less than 0.001 percent. Cyanide and thiocyanate were not determined, but if they had been present originally, the concentration of each would have been reduced to less than 0.001 percent.

\subsection{Preparation and Bromide Concentration of Separated Isotope Solutions}

The solutions of the purified $\mathrm{NaBr}^{79}$ and $\mathrm{NaBr}^{81}$ were filtered and transferred to $100 \mathrm{ml}$ volumetric flasks whose necks had been cut off so that only about $1 \mathrm{~cm}$ remained. The solutions were diluted to about $65 \mathrm{ml}$ and thoroughly mixed by swirling the flasks for several minutes. Each flask was then sealed with a rubber serum septum and allowed to stand over- 
night in the case of a semi-microbalance to insure thermal equilibrium. The flasks and contents were then weighed on the balance to $\pm 0.02 \mathrm{mg}$. Samples were withdrawn from each flask by inserting a stainless steel needle attached to a glass hypodermic syringe through the rubber septum and withdrawing the desired amount of solution. A second needle which just punctured the septum served as a vent. The syringe and needle were then washed with distilled water and the washings were combined with the bulk of the sample. The weight of the sample withdrawn was determined from the weight of the flask before and after the withdrawal of solution.

Four samples of from 7 to 9 grams each were withdrawn from each solution by this method. The quantity of bromide in each of these samples was from 2 to 3 meq. Each sample was transferred to a $100 \mathrm{ml}$ beaker and the syringe and needle were washed with distilled water, the washings being caught in the beaker with the bulk of the aliquot. The volume was adjusted to about $15 \mathrm{ml}$ by evaporation on a steam bath.

The bromide ion concentration of each solution was determined by constant-current coulometry using electrically generated silver ions. The end point of the silver titration was determined amperometrically. The details of the method are described by Marinenko and Taylor [15].

This procedure was first applied to solutions prepared from sodium bromide low in iodide and chloride. This sodium bromide was prepared in our laboratory since all of the commercially available sodium bromide was found to be high in chloride content. An excess of redistilled bromine was reacted with sodium carbonate solution. The resulting solution was evaporated to dryness and the mixture of sodium bromide and sodium bromate was heated to $550{ }^{\circ} \mathrm{C}$ to convert the bromate to bromide. The sodium bromide was then fused by heating in dry nitrogen to about $800{ }^{\circ} \mathrm{C}$ in a tube furnace. The iodide and chloride content of this $\mathrm{NaBr}$ was found to be less than 0.001 percent.

Three solutions of sodium bromide were prepared in the approximate concentration of the isotope solutions. Five to six samples each containing from 2 to 3 meq. of bromide ion were withdrawn from each solution and analyzed for bromide ion by the described method.

Data resulting from the analyses of these three preliminary bromide solutions showed that: (a) The meq. of bromide ion found by this method agreed to within 0.1 percent of the meq. calculated, and the assayed percentages were independent of sample size and concentration; and (b) The analyses of the three solutions were of equal precision.

The results of the bromide analyses of the separated isotope solutions are shown in table 1a for Groups I and table $1 \mathrm{~b}$ for Groups II. Pooling the results of these four sets of analyses with the three described above yields a value of $4.74 \times 10^{-5}$ meq. $\mathrm{Br} / \mathrm{g}$ solution as the standard deviation for an individual determination (27 degrees of freedom). The standard error of the mean of four determinations is therefore $2.37 \times 10^{-5} \mathrm{meq} . \mathrm{Br} / \mathrm{g}$ solution and that of five determinations is $2.12 \times 10^{-5} \mathrm{meq}$. $\mathrm{Br} / \mathrm{g}$ solution.

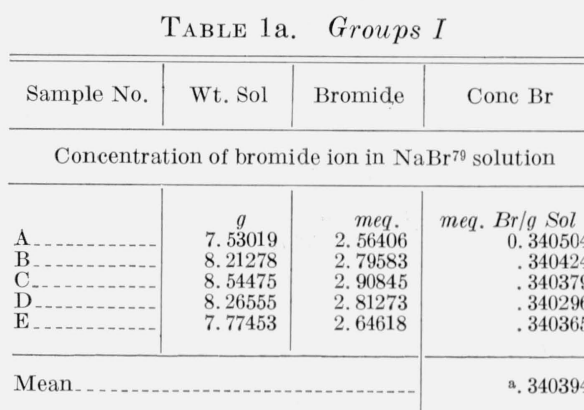

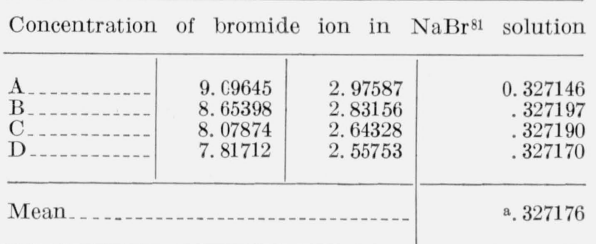

a The standard error of the mean is estimated to be $0.000024 \mathrm{meq} / \mathrm{g}$ sol. for the group with four analyses and 0.000021 for the group with five analyses, based on seven groups of data including the sets shown here.

TABLE 1b. Groups II

\begin{tabular}{l|l|l|l}
\hline \hline Sample No. & Wt. Sol & Bromide & Cone Br \\
\hline
\end{tabular}

Concentration of bromide ion in $\mathrm{NaBr}^{70}$ solution

\begin{tabular}{|c|c|c|c|}
\hline $\begin{array}{l}\mathrm{A} \\
\mathrm{B} \\
\mathrm{C} \\
\mathrm{D}\end{array}$ & $\begin{array}{c}g \\
7.77112 \\
7.88535 \\
7.32444 \\
7.73096\end{array}$ & $\begin{array}{c}\text { meq. } \\
2.810027 \\
2.851350 \\
2.648832 \\
2.795487\end{array}$ & $\begin{array}{r}\text { meq. Br/g Sol } \\
0.361599 \\
.361601 \\
.361643 \\
.361596\end{array}$ \\
\hline & & & a. 361610 \\
\hline
\end{tabular}

Concentration of bromide ion in $\mathrm{NaBr}^{81}$ solution

\begin{tabular}{l|r|r|r}
\hline & & & \\
$\mathrm{A}$ & 7.78525 & 2.74700 & 0.352847 \\
$\mathrm{D}$ & 7.78655 & 2.67682 & .352838 \\
$\mathrm{E} \ldots$ & 7.09924 & $2.5 \mathrm{C} 502$ & .352857 \\
\hline Mean _. & 7.47154 & 2.63715 & .352959 \\
\hline
\end{tabular}

a The standard error of the mean is estimated to be $0.000024 \mathrm{meq} / \mathrm{g}$ sol. based on seven groups of data including the sets shown here.

\subsection{Isotopic Analyses of the Solutions of the Separated Isotopes}

To avoid memory problems, one of the two solutions of the separated isotopes was analyzed on one mass spectrometer and the other solution on the other mass spectrometer. The sources were dismantled and thoroughly cleaned before and after each series of measurements. Blank analyses showed that clean sources yielded no bromine signals.

The isotopic compositions of the separated isotope solutions are given in table 2. The respective $\mathrm{Br}^{79}$ and $\mathrm{Br}^{81}$ isotopic compositions as reported by ORNL are: " $\mathrm{Br}^{79}$ ", $99.74 \pm 0.02$ atom percent $\mathrm{Br}^{79}, 0.26$ \pm 0.02 atom percent $\mathrm{Br}^{81}$; " $\mathrm{Br}^{81}$ ", $0.38 \pm 0.02$ atom 
percent $\mathrm{Br}^{79}, 99.62 \pm 0.02$ atom percent $\mathrm{Br}^{81}$. The ORNL limits quoted express the precision of the measurements. From known sources of systematic error, the absolute error is estimated by ORNL to be less than 1 percent.

\begin{tabular}{c|c}
$\begin{array}{c}\text { TABLE 2. Isotopic composition } \\
\text { of separated bromine isotopes } \\
\text { used in calibration samples }\end{array}$ \\
\hline \hline Isotope & $\begin{array}{l}\text { Isotopic composition a } \\
\text { (atom \%) }\end{array}$ \\
\hline $\mathrm{Br}^{79}$ & $\begin{array}{l}\mathrm{Br}^{79}=99.736 \\
\mathrm{Br}^{81}=0.264 \pm 0.008 \\
\mathrm{Br}^{79}=0.386 \pm 0.008 \\
\mathrm{Br}^{81}=99.614\end{array}$
\end{tabular}

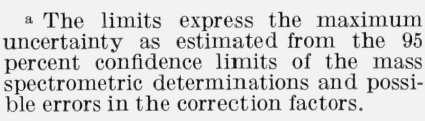

\subsection{Preparation of the Calibration Samples}

Six calibration samples were originally prepared (group I), but the results of sample No. 2 were subsequently discarded when the mass spectrometric data did not conform to the general pattern. In view of this it was considered desirable to prepare a completely new set of six calibration samples (group II).

All calibration samples were prepared by mixing portions of the $\mathrm{Br}^{79}$ and $\mathrm{Br}^{81}$ solutions, which were withdrawn and weighed in the manner already described. The ratios of $\mathrm{Br}^{79} / \mathrm{Br}^{81}$ ranged from 1.01 to 1.04 for group I and 0.94 to 1.13 for group II. For each determination, the portions for the calibration samples and the samples for the determination of the bromide concentration were withdrawn on the same day with the exception of sample $\mathrm{E}$ of the $\mathrm{Br}^{79}$ solution of group I and sample $\mathrm{E}$ of the $\mathrm{Br}^{81}$ solution of group II which were withdrawn two days after the rest of the group.

Each calibration sample was thoroughly mixed by stirring and $0.5 \mathrm{ml}$ of nitric acid was added. Twenty milliliters of $0.1 \mathrm{~N} \mathrm{AgNO} \mathrm{NO}_{3}$ solution were added to precipitate the bromide as silver bromide and the solution was allowed to stand overnight in the dark. The solution was filtered through filter paper and the precipitate of silver bromide was washed with dilute (1:500) nitric acid. The paper was carefully folded over the precipitate and both were dried in an electric oven at $110^{\circ} \mathrm{C}$. A weighed portion of the silver bromide was then transferred to a $4 \mathrm{ml}$ screwcap vial and sufficient concentrated ammonium hydroxide was added so that the resulting solution contained $3 \mathrm{mg}$ of bromide per milliliter of solution.

The isotopic ratio, $\mu$, of each calibration sample was calculated from

$$
\mu=\frac{g_{1}\left(1-f_{1}\right)+g_{2}\left(1-f_{2}\right)}{g_{1} f_{1}+g_{2} f_{2}}
$$

where

$g_{1}=$ meq. Br from $\mathrm{Br}^{79}$ soln

$g_{2}=$ meq. $\mathrm{Br}$ from $\mathrm{Br}^{81}$ soln

$f_{1}=$ mole fraction of 81 in $\mathrm{Br}^{79}$ soln $=0.00264$

$\left(1-f_{1}\right)=$ mole fraction of 79 in $\mathrm{Br}^{79}$ soln $=0.99736$

$f_{2}=$ mole fraction of 81 in $\mathrm{Br}^{81} \operatorname{soln}=0.99614$

$\left(1-f_{2}\right)=$ mole fraction of 79 in $\mathrm{Br}^{81}$ soln $=0.00386$.

The values of $g$ and $\mu$ are tabulated in table $3 \mathrm{a}$ for group I and in table $3 \mathrm{~b}$ for group II.

TABLE 3a. Group I-composition of calibration samples

\begin{tabular}{|c|c|c|c|c|c|}
\hline \multirow{2}{*}{$\begin{array}{c}\begin{array}{l}\text { Calibration } \\
\text { sample No. }\end{array} \\
\end{array}$} & \multicolumn{2}{|c|}{$\mathrm{NaBr}^{79}$ solution } & \multicolumn{2}{|c|}{$\mathrm{NaBr}{ }^{81}$ solution } & \multirow{2}{*}{$\begin{array}{c}\begin{array}{c}\text { Isotopic } \\
\text { ratio }\end{array} \\
\\
\mu \\
1.03000 \\
1.01972 \\
1.02666 \\
1.03992 \\
1.00999\end{array}$} \\
\hline & $\begin{array}{l}\text { wt sol } \\
2.20305 \\
2.03553 \\
2.07995 \\
2.11338 \\
2.17520\end{array}$ & $\begin{array}{c}\text { meq. Br } \\
g_{1} \\
0.749905 \\
.692882 \\
.708003 \\
.719382 \\
.740425\end{array}$ & $\begin{array}{l}w t \text { sol } \\
2.23035 \\
2.08166 \\
2.11262 \\
2.11904 \\
2.24607\end{array}$ & $\begin{array}{c}\text { meq. Br } \\
g_{2} \\
0.729717 \\
.681069 \\
.691199 \\
.693299 \\
.734860\end{array}$ & \\
\hline
\end{tabular}

TABLE 3b. Group II-composition of calibration samples

\begin{tabular}{|c|c|c|c|c|c|}
\hline Calibration & \multicolumn{2}{|c|}{$\mathrm{NaBr}^{79}$ solution } & \multicolumn{2}{|c|}{$\mathrm{NaBr}{ }^{\$ 1}$ solution } & Isotopic \\
\hline $\begin{array}{l}1 \\
2 \\
3 \\
4 \\
4 \\
5 \\
6 \ldots \ldots \ldots\end{array}$ & $\begin{array}{l}\text { wt sol } \\
1.04618 \\
1.09963 \\
1.09990 \\
1.09030 \\
1.18382 \\
1.10534\end{array}$ & $\begin{array}{c}\text { meq. Br } \\
g_{1} \\
0.378309 \\
.397637 \\
.397735 \\
.394263 \\
.428081 \\
.399702\end{array}$ & $\begin{array}{l}\text { wt sol } \\
\text { 1. } 08450 \\
\text { 1. } 09671 \\
1.10046 \\
1.09721 \\
1.07291 \\
1.20550\end{array}$ & $\begin{array}{c}\text { meq. Br } \\
g_{2} \\
0.382693 \\
.387002 \\
.388325 \\
.387178 \\
.378603 \\
.425391\end{array}$ & $\begin{array}{r}\mu \\
0.99104 \\
1.02982 \\
1.02658 \\
1.02068 \\
1.13256 \\
.94230\end{array}$ \\
\hline
\end{tabular}

\subsection{Isotopic Analyses of the Calibration Samples}

Although the bromine background signals were completely negligible during the analyses of natural samples, slight memory effects became evident during the analyses of the calibration samples. These samples were run alternatingly with the reference sample and memory effects on the order of 0.2 percent were evident when the calibration sample differed by 10 percent from the reference. To eliminate memory, a uranium sample was run before and after every sample that differed from the reference by more than 1 percent. The very high temperature achieved during the uranium runs served to remove any bromine from the previous analysis.

\subsection{Natural and Commercial Samples}

The reference sample is a commercial sample of sodium bromide designated as NBS Isotopic Reference Sample No. 106. A portion of this sample was converted to silver bromide in the same manner as the calibration samples.

The samples of commercial bromine were reacted with ammonium hydroxide solution and converted to silver bromide in the same manner as the calibration samples after making the solutions acidic with nitric acid.

The sylvites $(\mathrm{KCl})$, carnallites $\left(\mathrm{KMgCl}_{3} \cdot 6 \mathrm{H}_{2} \mathrm{O}\right)$, brines, sea water, and bittern were treated as follows: A measured quantity was dissolved in $500 \mathrm{ml}$ 
of $\mathrm{H}_{2} \mathrm{O}$ and $1 \mathrm{ml}$ of nitric acid was added. The solution was transferred to a distilling apparatus and, to remove iodine, $50 \mathrm{ml}$ of the solution was distilled into dilute ammonium hydroxide solution. Seventyfive milliliters of nitric acid were then added and the bromine produced was distilled into dilute ammonium hydroxide. Since chloride was the dominant halide in these samples, it was necessary to repeat the oxidation and distillation to free the bromine from chlorine. The bromide concentration in most of these samples ranged from 0.01 percent to 0.1 percent. After the second distillation, the solution was made acidic with nitric acid, converted to silver bromide, and the bromide ion concentration adjusted to $3 \mathrm{mg} \mathrm{Br} / \mathrm{ml}$, as in the case of the calibration samples.

The bromyrite sample $(\mathrm{Ag} \cdot \mathrm{Br})$ was dissolved in ammonium hydroxide and the silver was electrodeposited onto a platinum gauze electrode. The solution was made acidic and treated as the above minerals.

\section{Results and Discussion}

Table 4 compares the calculated isotopic ratios of 11 calibration samples with the results obtained on the two mass spectrometers. Two groups of calibration samples were prepared and the sources of both instruments were dismantled and cleaned between the analyses of the two groups. Table 5 shows the results of multiple analyses of the reference sample (12 per mass spectrometer per determination), both uncorrected and corrected for the biases indicated by the calibration samples. The reasons for the differences in bias cannot be quantitatively evaluated, but the major effect appears to be due to slight changes in the alinements of the source parts when they are reassembled after cleaning. In any case, the excellent agreement between all four corrected values of the reference indicates that the calibration method is consistent.

TABLE 4. Determination of mass spectrometric bias

\begin{tabular}{l|c|c|c|c|c|}
\hline \hline \multirow{2}{*}{$\begin{array}{l}\text { Calibration } \\
\text { sample No. }\end{array}$} & \multicolumn{2}{|c|}{ Isotopic ratio, $\mathrm{Br}^{70} / \mathrm{Br}^{81}$} & \multicolumn{2}{c}{ Correction factor (calc/M.S.) } \\
\cline { 2 - 5 } & Calc. & MS-1 & MS-4 & MS-1 & MS-4 \\
\hline
\end{tabular}

Group I

\begin{tabular}{l|l|l|l|l|l}
\hline & & & & \\
1 & 1.03000 & 1.02970 & 1.03035 & 1.000301 & 0.999670 \\
3 & 1.01972 & 1.02055 & 1.02120 & 0.999197 & .998561 \\
5 & 1.02666 & 1.02820 & 1.02865 & .998512 & .998075 \\
6 & 1.03992 & 1.04105 & 1.04125 & .998915 & .998723 \\
& 1.00999 & 1.01175 & 1.01235 & .998270 & .997679 \\
\hline Mean & & & .9990390 & .9985416
\end{tabular}

Group II

\begin{tabular}{l|l|l|l|l|l}
\hline & & & & \\
1 & 0.99104 & 0.99115 & 0.99270 & 0.999899 & 0.998328 \\
2 & 1.02982 & 1.02960 & 1.03225 & 1.000214 & .997646 \\
3 & 1.02658 & 1.02735 & 1.02875 & 0.999260 & .997900 \\
5 & 1.02068 & 1.02125 & 1.02270 & .999442 & .998025 \\
6 & 1.13256 & 1.13185 & 1.13425 & 1.000627 & .998510 \\
\hline Mean & 0.94230 & 0.94185 & 0.94355 & 1.000478 & .998675 \\
\hline
\end{tabular}

TABLE 5. Observed and corrected values of the $\mathrm{Br}^{79} / \mathrm{Br}^{81}$ ratio for the reference sample

\begin{tabular}{ll|l|r|r}
\hline \hline & $\begin{array}{c}\text { Observed } \\
\text { ratio }\end{array}$ & $\begin{array}{c}\text { Correction } \\
\text { factor }\end{array}$ & Corrected ratio \\
\hline Group I MS-1 & 1.028792 & 0.9990390 & 1.027807 \\
MS-4 & 1.029592 & .9985416 & 1.028090 \\
Group II MS-1 & 1.027683 & .9999866 & 1.027669 \\
MS-4 & 1.029675 & .9981807 & 1.027803
\end{tabular}

Mean.

$1.02784 \pm 0.00105$ a

a Uncertainty components:
95 percent confidence limits on ratio determination...
Possible error in composition of separated isotopes.
Possible error in calibration samples...

Table 6 summarizes the bromine isotopic-ratio measurements of samples of commercial bromine and the original bromine source material as supplied by seven major bromine manufacturers in the United States. Table 7 summarizes the results of measurements on a number of mineral samples. The results show that there are no significant isotopic variations among any of the commercial and natural samples. The average $\mathrm{Br}^{79} / \mathrm{Br}^{81}$ ratio of the 29 samples is displaced from the reference by -0.00048 . Most of this shift is due to the mineral samples which yield the lowest ratios. This result is consistent with previous experience at this laboratory on other elements. It may be attributed to a difference in purity between the mineral samples and the reference. In general it is more difficult to obtain standard intensity levels during mass spectrometric analyses of natural samples as compared to reference samples [1] and it was observed that the $\mathrm{Br}^{79} / \mathrm{Br}^{81}$ ratios obtained in the more difficult (higher filament temperature) analyses were consistently lower than those obtained in the less difficult (lower filament temperature) analyses.

TABLE 6. Isotopic abundance ratios of bromine from various commercial bromine and bromine source materials relative to reference sample

\begin{tabular}{|c|c|c|}
\hline Sample & Source & $\begin{array}{c}\text { A verage } \\
\text { observed } \\
\text { ratio of } \\
\text { ratios a }\end{array}$ \\
\hline Brine, Searles Lake... & American Potash \& Chemical & 0.9988 \\
\hline Brine .... & Arkansas Chemical Co & .9996 \\
\hline Bromine ...... & Arkansas Chemical Co & .9995 \\
\hline Monroe brine & Dow Chemical $\mathrm{Co}_{2}$ & .9994 \\
\hline Midland bromine, purified. & Dow Chemical $\mathrm{Co}_{-}$ & .9998 \\
\hline Freeport bromine, purified .. & Dow Chemical Co & .9995 \\
\hline Sea Water & Ethyl-Dow Chemical Co & .9992 \\
\hline Bittern & F. M. C. Corp & .9994 \\
\hline Bromine... & F. M. C. Corp & .9990 \\
\hline Brine. ............ & Great Lakes Chemical Corp & .9999 \\
\hline Brine ....... & Great Lakes Chemical Corp__... & .9998 \\
\hline Brine.... & Great Lakes Chemical Corp & 1. 0005 \\
\hline Brine ... & Great Lakes Chemical Corp & 0.9998 \\
\hline Bromine . & Great Lakes Chemical Corp & .9999 \\
\hline Bromine & Great Lakes Chemical Corp.... & .9998 \\
\hline Bromine _..._. & Great Lakes Chemical Corp & 1. 0002 \\
\hline Bromine & Great Lakes Chemical Corp & 0.9998 \\
\hline Brine, St. Louis production & Michigan Chemical Corp & 1.0002 \\
\hline Bromine, St. Louis production & Michigan Chemical Corp....... & 1. 0000 \\
\hline Bromine, Manistic production & Michigan Chemical Corp & 0.9994 \\
\hline Bromine, El Dorado production & Michigan Chemical Corp..... & .9992 \\
\hline
\end{tabular}


TABLE 7. Isotopic abundance ratios of bromine from some minerals relative to reference sample

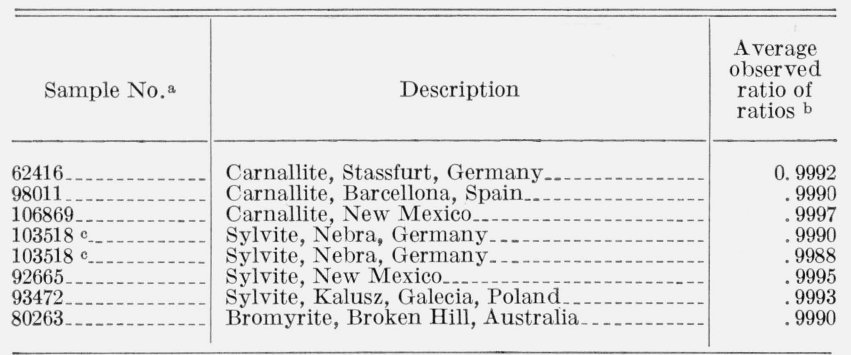

a U.S. National Museum Catalog numbers.

$\mathrm{b}\left(\mathrm{Br}^{79} / \mathrm{Br}^{81}\right)$ sample/( $\left.\mathrm{Br}^{79} / \mathrm{Br}^{81}\right)$ reference. The 95 percent confidence limit is \pm 0.0012 .

'Two pieces from the same sample.

The possibility of slight isotopic fractionation during the extraction of the trace amounts of bromine in the natural samples cannot be completely discarded, but is considered extremely unlikely in view of the high recovery techniques used.

A term to cover a possible natural variation of \pm 0.00085 (the range of results for the natural samples) in the $\mathrm{Br}^{79} / \mathrm{Br}^{81}$ ratio has been included in the error attached to the final atomic weight value (tables 8 and 9 ).

The absolute ratio, $\mathrm{Br}^{79} / \mathrm{Br}^{81}=1.0274 \pm 0.00105$, for the refererence sample results in the percentage abundances: $\mathrm{Br}^{79}=50.686 \pm 0.025$ and $\mathrm{Br}^{81}=49.314$

TABLE 8.-Summary calculation of the atomic weight of bromine

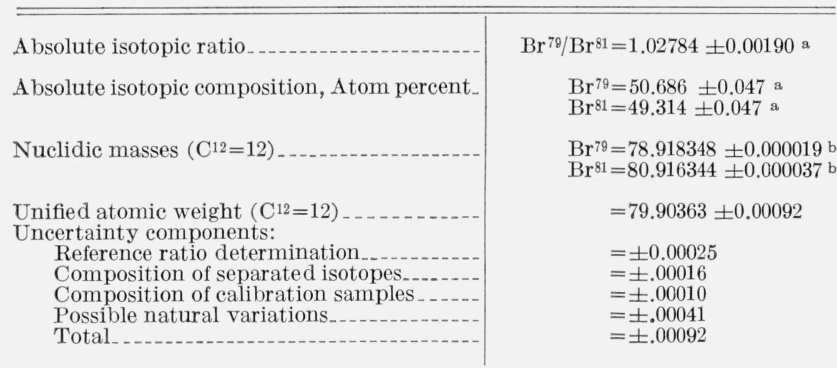

a The uncertainties are overall limits of error based on 95 percent confidence limits for the mean and allowances for the effects of known sources of possible systematic error (See table 5) plus a component (.00085, in the ratio) to cover possible natural variations in the $\mathrm{Br}^{79} / \mathrm{Br}^{81}$ ratio.

b From ref. [16]. \pm 0.025 . The uncertainties are the sum of the 95 percent confidence limits on the ratio determination and the estimated maximum possible errors in the analyses of the separated isotopes and the compositions of the calibration samples. Using the nuclidic masses given by Everling et al. [16], the results yield an atomic weight of $79.90363 \pm 0.00051$ on the unified scale $\left(\mathrm{C}^{12}=12\right)$. These calculations are summarized in table 8 where the error statements include the effect of possible natural variation to the extent noted previously.

The atomic weight of bromine reported here is significantly different from that accepted by the International Commission on Atomic Weights (1961), $79.909 \pm 0.002\left(\mathrm{C}^{12}=12\right)$, which was derived by the use of a combining weight for $\mathrm{AgBr} / \mathrm{Ag}=1.740785$ and the Commission's value of 107.870 for the atomic weight of silver. Using the herein determined value of 79.90363 for bromine and the silver value of 107.8682 from Shields et al.[1] gives a combining weight ratio $\mathrm{AgBr} / \mathrm{Ag}=1.740752$. Table 9 summarizes the atomic weight results on silver, chlorine and bromine obtained in this laboratory using the same mass spectrometers and the same calibration technique. Also shown are the calculated combining weight ratios of $\mathrm{AgCl} / \mathrm{Ag}$ and $\mathrm{AgBr} / \mathrm{Ag}$.

The authors are indebted to George Marinenko for the coulometric titrations of the bromide in the separated isotope solutions and to $\mathrm{H}$ sein $\mathrm{H}$. $\mathrm{Ku}$ for the statistical analysis of the experimental data. They also express their appreciation to Dr. George Switzer and the U.S. National Museum for supplying the mineral samples and to the following companies for supplying the bromine and brine samples: American Potash \& Chemical Corp., Los Angeles, Calif.; Arkansas Chemicals, Inc., El Dorado, Ark.; The Dow Chemical Co., Midland, Mich.; EthylDow Chemical Co., Freeport, Tex.; F. M. C. Corporation, Newark, Calif.; Great Lakes Chemical Corp., Filer City, Mich.; Michigan Chemical Corp., Saint Louis, Mich.

TABLE 9.-Summary of National Bureau of Standards mass spectrometric atomic weight determinations (C $\left.{ }^{12}=12\right)$ of silver, chlorine and bromine

\begin{tabular}{|c|c|c|c|}
\hline Element & Absolute isotopic ratio & Nuclidic mass a & Atomic weight \\
\hline$A g b_{-}$. & $\mathrm{Ag}^{107 / \mathrm{Ag}^{100}=1.07597 \pm 0.00135}$ & $\begin{array}{ll}\mathrm{Ag}^{107}=106.904970 & \pm 0.000110 \\
\mathrm{Ag}^{109}=108.904700 & \pm 0.000110\end{array}$ & $107.8682 \pm 0.0010$ \\
\hline $\mathrm{Cl}$ & $\mathrm{Cl}^{35} / \mathrm{Cl}^{37}=3.1272 \quad+0.0079$ & $\begin{array}{l}\mathrm{Cl}^{35}=34.9688545 \pm 0.0000028 \\
\mathrm{Cl}^{37}=36.9658959 \pm 0.0000022\end{array}$ & $35.45273+{ }_{-0.00097}^{0.00092}$ \\
\hline $\mathrm{Br}$ & $\mathrm{Br}^{70} / \mathrm{Br}^{81}=1.02784 \pm 0.00190$ & $\begin{array}{ll}\mathrm{Br}^{79}=78.918348 & \pm 0.000019 \\
\mathrm{Br}^{81}=80.916344 & \pm 0.000037\end{array}$ & $79.90363 \pm 0.00092$ \\
\hline
\end{tabular}

\footnotetext{
a See reference [16] 


\section{References}

[1] W. R. Shields, E. L. Garner, and V. H. Dibeler, J. Res. NBS 66A (Phys. and Chem.), 1 (1962).

[2] W. R. Shields, T. J. Murphy, E. L. Garner, and V. H. Dibeler, J. Am. Chem. Soc. 84, 1519 (1962).

[3] J. P. Blewett, Phys. Rev. 49, 900 (1936).

[4] D. Williams and P. Yuster, Phys. Rev. 69, 556 (1946).

[5] J. R. White and A. E. Cameron, Phys. Rev. 74, 991 (1948).

[6] A. E. Cameron and E. L. Lippert, Jr., Science 121, 136 (1955).

[7] W. F. Hillebrand, G. E. F. Lundell, H. A. Bright, and J. I. Hoffman, Applied Inorganic Analysis, $2 \mathrm{~d}$ ed., p. 726 (John Wiley \& Sons, New York, N.Y., 1953).

[8] T. J. Murphy, W. S. Clabaugh, and R. Gilchrist, J. Res. NBS 53, 13 (1954).
[9] E. Abel, Monatsh. 81, 339 (1950).

[10] O. Masson, J. Chem. Soc. 91, 1449 (1907).

[11] F. Schuster, Z. anorg. allgem. Chem. 186, 253 (1930).

[12] E. Halfpenny and P. L. Robinson, J. Chem. Soc. 1952, 928.

[13] R. Uzel, Coll. Czech. Chem. Commun. 5, 139 (1933).

[14] N. Allen, Ind. Eng. Chem., Anal. Ed. 2, 55 (1930).

[15] G. Marinenko and J. K. Taylor, J. Res. NBS 6zA (Phys. and Chem.), 31 (1963).

[16] F. Everling, L. A. König, J. H. E., Mattauch, and A. H. Wapstra, Nuclear Phys. 18, 529 (1960).

(Paper 68A6-306) 